\title{
Advocacy: Achieving Physician Competency
}

\author{
Jonathan E. Fried, $B A^{7,2}$, Scott A. Shipman, $M D, M P H^{3,4}$, and Laura L. Sessums, JD, MD 5 \\ Check for

${ }^{1}$ Harvard Medical School, Boston, MA, USA; ${ }^{2}$ John F. Kennedy School of Government at Harvard University, Cambridge, MA, USA; ${ }^{3}$ Association of American Medical Colleges, Washington, DC, USA; ${ }^{4}$ The Dartmouth Institute for Health Policy \& Clinical Practice, Lebanon, NH, USA; 5 Uniformed Services University of the Health Sciences, Bethesda, MD, USA.

J Gen Intern Med 34(11):2297-8

DOI: $10.1007 / \mathrm{s} 11606-019-05278-y$

(c) Society of General Internal Medicine 2019

\section{A} 11 clinicians confront patient needs they cannot meet within the confines of the clinical encounter. We discover that our patients are not filling prescriptions because the cost of their medications has skyrocketed. We discharge asthmatic children to homes filled with mold, and schizophrenic patients without secure housing to the street. In residency, we learn to care and advocate for individual patients, but when do we learn to advocate for solutions to systemic problems that negatively affect the health of our patients and the communities we serve?

Only twenty percent of variation in health outcomes can be attributed to direct clinical care. ${ }^{1}$ Through advocacy, clinicians can influence the other eighty percent-the socioeconomic and environmental conditions resulting from policies and programs that affect health in their own communities, like clean water and air, access to needed health care, and affordable housing. Many examples of clinician-driven advocacy exist, like the Medical Society Consortium on Climate and Health and the \#ThisIsOurLane movement. But for many of us, our responsibility to treat and prevent disease in individual patients leaves little time for anything else. Burnout is now an epidemic among health care professionals, perhaps in part because we feel powerless in the face of systemic or structural barriers that affect our patients' health. Moreover, many of us lack the knowledge, skills, and resources needed to impact the full spectrum of factors affecting our patients' health. ${ }^{2}$ While many physicians are civic-minded and engage in some form of advocacy during medical school, only about one-quarter in one survey engaged in advocacy during residency. ${ }^{3,4}$ How do we close the gap between our intentions and our actions?

Howell et al. offer one answer: advocacy training during graduate medical education (GME). ${ }^{5}$ Performing the first systematic review of published advocacy curricula for medical trainees, the authors identified 38 articles, summarizing each program's educational content and teaching methods while

Prior Presentations This manuscript was not previously presented at any conferences.

Published online August 16, 2019 identifying common facilitators of and barriers to curriculum implementation. Although $84 \%$ of curricula included in their sample are from primary care-related specialties - especially pediatrics-most are useful resources that are applicable across all medical and surgical specialties. Consistent with prior research showing that training in advocacy during residency is associated with higher levels of community involvement and advocacy skill later on, ${ }^{6}$ Howell et al. call for all trainees to be "educated in advocacy skills, knowledge, and attitudes." We support their call for all residents to gain skills in advocacy, and further, we support a lifetime learning approach to advocacy extending from medical school through continuing medical education (CME).

Many professional medical societies include patient-, practice-, system-, and population-level advocacy among physicians' professional responsibilities, including the American Medical Association, the American Academy of Pediatrics, and over one hundred others. ${ }^{7}$ We agree for several reasons. First, the benefits granted to the profession, including autonomy, self-regulation, and a status of trust as a leading authority on health, come with reciprocal obligations to society. Influencing institutional and public policies to improve health allows physicians to demonstrate their commitment to these societal responsibilities. Additionally, physicians' expertise and access to patient narratives leave them distinctly qualified to observe the human impact of policies affecting patients, to identify root causes and necessary solutions, and to raise these issues in public discourse. Engaging with the systems and policies that produce poor health outcomes enables physicians to exert greater influence on their own patients' health outcomes, mitigating the sense of powerlessness that frequently exists in the face of complex, multifactorial drivers of poor health. Finally, physicians increasingly hold financial accountability for the health of populations. Engaging with the upstream factors that drive eighty percent of health outcomes will increasingly be an essential part of effective health care and will be necessary to avoid the risk of financial penalties. Advocacy is a natural extension of these efforts.

As with clinical care, advocacy is a team sport. Just as a health care team with a diverse set of perspectives and skills is needed to effectively and comprehensively meet the needs of patients, physicians can serve as members of "advocacy teams" alongside patients, politicians, scholars, activists, and other health care professionals, among others. By advocating 
in partnership with other stakeholders, physicians can achieve more than by advocating alone. Effective teamwork in advocacy requires interprofessional training, just as clinical teambased care does.

To incorporate advocacy training into American graduate medical education, we call on the Accreditation Council for Graduate Medical Education (ACGME) to expand its definition of advocacy. ACGME Common Program Requirements currently require all residents to demonstrate competence in advocating for "quality patient care and optimal patient care systems" and for "patients within the health care system." ACGME rightly recognizes that not all advocacy is political, and that physicians can make a meaningful difference by advocating for change within their own clinics and health systems. We believe these requirements should also encompass efforts to improve population health and reduce health disparities from outside the health care system, through efforts such as policy advocacy and community engagement. In turn, Residency Review Committees (RRCs) should require programs to offer advocacy instruction or experience. Howell et al. noted that, in 2001, the ACGME Pediatric RRC began requiring at least two ambulatory educational units involving community pediatrics and child advocacy. Not surprisingly, this appeared to drive development and adoption of advocacy curricula within pediatric residency programs. ${ }^{8}$

Specialty societies can also play an important role in extending physician competency in advocacy. The American Academy of Pediatrics (AAP) has created the Community Pediatrics Training Initiative, which offers advocacy training grants and supports visiting professorships to spread curriculum development and adoption. Other specialty societies could follow this lead, developing specialty-specific training initiatives and toolkits, potentially following the blueprint of experienced peer specialty organizations like the AAP. Because many advocacy skills are generalizable across specialties, sharing curricula on electronic platforms for clinician educators - such as the Association of American Medical Colleges' open-access journal MedEdPORTAL (www. mededportal.org) - could catalyze the spread of effective resources for multiple specialties to use to train the next generation of physician-advocates.

We share Howell et al.'s concern about the hurdles to creating a self-sustaining culture of advocacy. It requires competent role models and mentors, as well as protected time for busy trainees who may be ready to confront an injustice but are unsure how to do so. Universities, health systems, professional societies, and philanthropic entities must lead the way by providing the necessary resources for curriculum development and deployment, faculty development and recruitment, and advocacy-related scholarship.

Of course, program directors must balance advocacy with other educational objectives. This could be accomplished by allowing advocacy electives to substitute for other non-clinical electives in research, quality improvement, patient safety, and social medicine. Alternatively, community-organizing and advocacy efforts could be used to satisfy programmatic scholarship requirements, using standardized formats like the Advocacy Portfolio to document projects. ${ }^{9}$ Advocacy education is not one-size-fits-all: Howell et al. show the extraordinary variation in time commitment among published curricula, which range from extensive longitudinal group projects and month-long courses to half-day workshops, weekend visits to state capitols, and one week's worth of noon conferences. Advocacy education in residency should be part of a continuum of learning starting in medical school and continuing via CME after entering practice. As such, GME-based advocacy training need not be overly burdensome nor time-consuming.

When equipped with the right tools, physicians can be remarkably effective at informing, shaping, and driving public debates about the systems and policies that cause patients' health to flourish or fail. Our profession has an opportunity and an obligation to educate and prepare the next generation of physicianadvocates, and to commit the resources necessary to do so. We must teach trainees to identify health problems caused by systemic or structural issues that cannot be solved in the exam room or at the bedside, and to endow them with the skills to confront them.

Contributors: There were no significant contributors to this manuscript outside of those included in the authorship group.

Corresponding Author: Laura L. Sessums, JD, MD; Uniformed Services University of the Health Sciences, Bethesda, MD, USA (e-mail: sessula@gmail.com).

\section{Compliance with Ethical Standards:}

Conflict of Interest: The authors declare that they do not have a conflict of interest.

\section{REFERENCES}

1. Hood CM, Gennuso KP, Swain GR, Catlin BB. County Health Rankings: relationships between determinant factors and health outcomes. Am J Prev Med. 2016;50(2):129-35.

2. Sessums L, Dennis L, Liebow M, Moran W, Rich E. Health Care Advocacy: A Guide for Busy Clinicians. New York: Springer; 2011.

3. Gruen RL, Campbell EG, Blumenthal D. Public roles of US physicians: community participation, political involvement, and collective advocacy. JAMA. 2006;296(20):2467-75.

4. Stafford S, Sedlak T, Fok MC, Wong RY. Evaluation of resident attitudes and self-reported competencies in health advocacy. BMC Med Educ. 2010;10:82.

5. Howell BA, Kristal RB, Whitmire LR, Gentry M, Rabin TL, Rosenbaum J. A systematic review of advocacy curricula in graduate medical education. J Gen Intern Med. 2019.https://doi.org/10.1007/11606. 1525-1497

6. Community Pediatrics Training Initiative Workgroup Minkovitz CS, Goldshore M, Solomon BS, Guyer B, Grason H. Five-year follow-up of Community Pediatrics Training Initiative. Pediatrics. 2014;134(1):83-90.

7. ABIM Foundation, et al. Medical professionalism in the new millennium: a physician charter. Ann Intern Med. 2002;136(3):243-6.

8. Solomon BS, Minkovitz CS, Grason HA, Carraccio C. Community pediatrics: a consistent focus in residency training from 2002 to 2005 . Ambul Pediatr. 2007;7(4):321-4.

9. Nerlinger AL, Shah AN, Beck AF, et al. The Advocacy Portfolio: a standardized tool for documenting physician advocacy. Acad Med 2018;93(6):860-8.

Publisher's Note Springer Nature remains neutral with regard to jurisdictional claims in published maps and institutional affiliations. 